Could Ecologically Sound Human Nutrition Include the Consumption of Animal Products?

This is the author's own version of the chapter published as follows:

J. Deckers, Could Ecologically Sound Human Nutrition Include the Consumption of Animal Products?, in J. Sabaté (ed.), Environmental Nutrition. Connecting Health and Nutrition with Environmentally Sustainable Diets, Academic Press, 2019, pp. 229-242. 


\section{Could Ecologically Sound Human Nutrition Include the Consumption of Animal Products?}

\section{Abstract:}

This chapter focuses on the role of animal products in human nutrition. I will describe and discuss three cases to address whether people who consume animal products adopt ecologically sound diets, highlighting that there is no simple 'yes' or 'no' answer to this question. The reason for this variation stems from the need to consider people's ecological contexts. In all contexts, we must embrace an unconditional duty to act in accordance with our all-encompassing holistic health interest. This general interest comprises multiple specific, and sometimes competing interests, including seven interests in avoiding the consumption of animal products.

\section{Key words:}

animal, ecology, ethics, nutrition, policy, politics, veganism

\section{Introduction}

The concept of 'environmental nutrition' does not, per se, appear to have a normative definition as it refers merely to the trivial fact that all nutrition is the consumption of something that is part of one's environment. ${ }^{1}$ However, there is no doubt that many use this concept as shorthand for 'environmentally-responsible nutrition', particularly to highlight that many human dietary practices

\footnotetext{
${ }^{1}$ I would like to thank Marcus Ventin, Abigail Clarke, Isaac Moore, and an anonymous reviewer for their helpful comments on an earlier version.
} 
are out of kilter with our ecological responsibilities and that alternative eating practices should therefore be adopted (Sabaté, J., Harwatt, H., \& Soret, S., 2016).

In this chapter, I consider whether and when the human consumption of animal products can be environmentally, or better, ecologically sound. I prefer the latter term as the word 'environment' tends to be used to refer to 'that which surrounds the world of human beings', perhaps suggesting erroneously that people can be separated from the planetary ecosystem. The word ecology, by contrast, refers to 'the study of the house (the meaning of the Greek word for 'eco') in which we all live', where the word 'house' in this context does not refer to a building, but to our ecosystem. The normative connotations that may be associated with the concept of 'ecological human nutrition' must be understood in light of the aim to ensure that human nutrition is ecologically sound. Given that human beings are integral parts of the global ecosystem, for a diet to be ecologically appropriate, it must therefore also be socially sound.

In my book 'Animal (De)liberation' (Deckers, 2016), I argued that the human consumption of animal products can only be ecologically sound if we carefully balance our interest in consuming animal products against seven competing interests in:

' 1 / avoiding the consumption of animals, including those who die naturally or accidentally, which is based on a more general animalist interest.

2 / avoiding the consumption of animals who are closely related to us, which is based on a more general evolutionist interest.

3 / avoiding the consumption of animal products where such consumption relies on the intentional infliction of pain, suffering, and death upon animals.

4/ avoiding the consumption of animal products where such consumption relies on the intentional infliction of pain, suffering, and death upon animals who are closely related to us. 
5 / avoiding the consumption of animal products where such consumption relies on the intentional infliction of pain, suffering, and death upon animals with relatively great capacities for richness of experience.

6/ avoiding the consumption of animal products where such consumption relies on actions that pose relatively high risks of inflicting accidental pain, suffering, and death upon animals.

$7 /$ avoiding the consumption of animal products where such consumption relies on actions that jeopardise the integrity of nature' (Deckers, 2016, p. 159-160).

Whereas these interests are specific, I also argued that our general holistic health interest (interest 8) is paramount. It includes all these, as well as other specific interests, for example an interest in eating animal products. When Aiking (2019) writes that people 'are more susceptible to health incentives than to sustainability incentives', he may be right that some words may be more successful in bringing about change than others. However, if we understand the concept of health holistically, a concern about one's health includes a concern about one's psychological, and therefore also one's moral health, which cannot be obtained without a concern with sustainability. To enjoy good moral health, moral agents must plan well for the future. However, the moral health of many people is far from holistic as the effects of many contemporary human diets will, amongst many other things, severely compromise the ability of future generations to feed themselves. In the first chapter of my book, I discussed the role of the consumption of animal products in this regard (Deckers, 2016, p. 13-50), documenting that its negative Global Health Impact (GHI) on living and future organisms generally greatly exceeds the negative $\mathrm{GHI}$ associated with the human consumption of other products. In earlier work, the concept of GHI was introduced as a unit to compare the overall impact of any human action with that of another on the health of biological organisms (Deckers, 2011).

Whereas the concept of an evolutionist interest was originally intended to refer to our interest in attributing greater moral significance to animals who are more closely related to us 
compared to others (Deckers, 2016), this interest can also be applied to other organisms (Paez, 2017; Deckers, 2017). The basic idea is that, we ought to have an interest in valuing an organism A more than an organism B if, all else being equal, $A$ is more closely related to us. This implies that our animalist interest should be seen as a sub-class of our evolutionist interest. I argued that this interest should apply also to comparing our bonds with A and B after they have died, and that it is because of this interest that we ought to have greater reservations towards eating the bodies of those who are more closely related to us. This is why many of us may feel a greater aversion towards doing so.

Whereas 'Animal (De)liberation' set out the basic theoretical framework, it provided few examples of how these interests ought to be balanced in practice. In this chapter I will provide examples of situations where these interests can be invoked rightly or wrongly to justify the consumption of animal products. In doing so, it will become clear that the question of when the consumption of particular animal products can be justified depends on a careful assessment of one's ecological context. Our diets will be ecologically sound if they safeguard our interests in holistic health, but what is healthy in one situation will not necessarily be healthy in another context. The three cases that are used to illustrate this point are fictional, and have been chosen deliberately to represent difficult dietary dilemmas. Through further discussion, I hope that further insight will emerge in relation to how to solve these as well as other dietary dilemmas.

\section{Case 1: Jackie in the jungle}

Jackie finds herself in the jungle. After she and her friend Lisa had lost their way, Lisa fell ill and died. Jackie is hungry, but she recognises that she has an evolutionist interest, which is why she thinks that consuming Lisa would be wrong. Just after Lisa's death, Jackie stumbles upon a dead chimpanzee. She recognises an aversion towards eating a part of him because of her evolutionist interest, but she also feels inclined to do so. The alternative would be to harvest some root 
vegetables and some fruits, which would require slightly more effort. She decides not to eat the chimpanzee and to eat a meal obtained from plants instead.

\section{Evaluation}

The idea of eating the chimpanzee may be expected to fill Jackie with morally relevant disgust (Mahoney, 2017). Whereas Jackie may have suppressed this feeling, I believe that Jackie should act in accordance with her evolutionist interest, which demands that the chimpanzee is granted great moral significance, even when dead. Whilst I think that granting such significance demands that she does not regard the chimpanzee as an object for consumption, I also think that some changes to the scenario would alter this conclusion. Examples of such changes include: Jackie needing to expend significantly more effort to procure a vegetable meal or Jackie not being able to find a vegetable meal that would be nutritionally balanced. In both cases, Jackie would jeopardise her physical wellbeing, an important dimension of her interest in holistic health (interest 8). I believe that Jackie would also be justified in eating a part of the chimpanzee where the only alternative option to obtain sufficient protein would necessitate the killing of animals (interest 3). I also think that our evolutionist interest should stand in the way of eating Lisa, unless Jackie found herself in a dire situation where a failure to do so would be highly likely to result in starvation.

Imagine, however, a slightly different scenario where Jackie did not find a chimpanzee, but a black guinea fowl brooding on a clutch of eight eggs, as well as six freshwater mussels. Given Jackie's uncertainty about obtaining sufficient protein, she decides to kill in order to eat. She wonders, however, which animal or animals she should kill: the brooding fowl, some of her eggs, or the mussels. Jackie thinks that half the clutch of eggs would provide her with about the same amount of nutrition as eating the four mussels. She decides to let the fowl live, and to eat half the clutch of eggs, thinking that the mature mussels may be capable of enjoying richer experiences than the guinea fowl embryos. Whilst I doubt whether this might be so, I think that she may make the right choice. Animals who are more closely related to us should not always be prioritised over those who 
are more distantly related as we should also consider differences in experiential capacities (interest 5). Had Lisa still been alive, however, Jackie should refrain from killing her even if her capacities were, due to illness, inferior to those of the guinea fowl (interest 4).

\section{Case 2: Kasana the Maasai man}

Kasana is a Maasai man. The Maasai live in Kenya and Tanzania, where they live semi-nomadic lives, keeping cows, bulls, and their offspring. He justifies keeping these by claiming that he would not be able to flourish without relying on consuming their blood, milk, and flesh. Kasana's body is welladapted to consuming large quantities of animal products as his genome includes genes for lactase persistence, granting him the ability to digest lactose after infancy, as well as genes that cater for an exceptionally good capacity to regulate cholesterol (Wagh, Bhatia, Alexe, et al., 2012). Kasana is aware of the fact that the Maasai's way of living intentionally inflicts pain, suffering, and death on animals, but he believes that this is justified because of interest 8 . He is aware that some people object to the ways in which the Maasai use animals, but he thinks that pastoralism is preferable to crop agriculture for several reasons:

$1 /$ It provides greater food security for agronomic reasons as the area in which he lives has traditionally not been very suitable for agriculture. Kasana thinks that pastoralism is preferable as there is too little rain to support reliable crop agriculture, a situation that is aggravating because of climate change. Kasana is aware that new genetic variants of traditional crops, as well as water pump and storage technologies, may be able to mitigate this situation to some extent. However, in spite of these new technologies, Kasana does not think that crop agriculture, or any other methods by which people could obtain food from the land, could provide greater food security for his family. Whereas animals can move to other areas in periods of drought, crops cannot do so. In addition, ploughing the land causes land degradation, including soil erosion and desertification. Soil erosion is 
also worsened by irrigation, which relies on the use of precious resources, including energy and water. The use of these resources and their negative GHIs jeopardise the long-term capacity of the land to provide food for people. Kasana knows that his animals also produce negative GHIs, but he thinks that crop agriculture would produce more negative GHIs to obtain the same quantity of food with comparable nutritional value.

2/ It provides greater food security for personal and social reasons. Kasana believes that some Kenyans and Tanzanians may be able to flourish thanks to modern technologies used in crop agriculture, but he has much greater faith in the age-old pastoralist methods of the Maasai's way of life. New plant breeds and technologies that have been developed in Europe and the USA are alien to him, but the Maasai's way of life is in his blood. Kasana is also aware of the fact that much land that is used for crop agriculture has been expropriated forcibly from pastoralists, jeopardising the culture of the Maasai (Hughes, 2006; Nganga, 2013; Talbot, 1986). As he believes in restitutive justice, he thinks that the land that has been taken from the Maasai pastoralists should be returned to them. He also thinks that, if he joined the growing trend towards crop agriculture, it would increase pressure on pastoralists.

3/ Kasana considers the impacts upon nonhuman nature. He knows that the Maasai's creation story prohibits 'breaking the ground' as the 'soil [is] sacred on account of its producing grass' (Finke, 2003). He believes that this stems in part from a concern with the accidental infliction of pain, suffering, and death upon animals (interest 6), as well as from a concern with the integrity of nonhuman nature (interest 7), which would be jeopardised by ploughing and irrigation.

\section{Evaluation}

These are powerful reasons. With regard to the first reason, research has shown that, in many situations, vegan diets present a smaller risk to human food security (Springmann, 2019). In a 
previous work, I also speculated that a predominantly vegan global agricultural system may provide at least as much human food security as a more mixed agricultural system (Deckers, 2016). As the former system does not exist, this remains to be seen. A world with a totally vegan agricultural system wherein no wild or feral animals would be eaten either, however, is likely to compromise human food security. One reason for this lies in the fact that a large amount of land is either unsuitable for crop production or would be degraded significantly by it. Whilst a totally vegan human population may still use this land for food, for example by harvesting wild fruits and berries, the feeding potential of grassland would be lost as people are unable to digest cellulose, unlike animals who graze and browse. Whilst land that is currently being used for grazing by pastoralists could increase its potential to fulfil other important functions, for example that of mitigating climate change through the increase in tree cover that is likely to result from a reduction in grazing pressure, the benefits provided by these other functions may not necessarily outweigh the benefits of grazing. If we assume, however, that a predominantly vegan global agricultural system could provide at least as much human food security as a more mixed agricultural system, it would not be sufficient to reject Kasana's way of life. Whilst food security might be enhanced globally, it may not do so locally. It would be unreasonable to expect Kasana to compromise the needs of his family for the potential gains that may be associated with the adoption of a predominantly vegan global agricultural system. The reason why such a system may not provide as much local food security may stem from agronomic or social reasons, where neither can be ignored. Even if a good case could be made to support the view that the agronomic obstacles could be overcome so that Kasana might be able to enjoy as much food security under a local vegan agricultural system as under his current herding-gathering system, the adoption of such a system might still be objectionable for social reasons. The Maasai might perceive the suggestion that such a system should be adopted as yet another threat to their culture, driven by an absolutist ideology, for example Francione's (2010) view that all human beings should, in all situations, adopt vegan diets. This ideology should not be imposed on the Maasai as its implementation would not be justifiable without their support, 
obtained through a just political process. Sufficient evidence would need to be both provided and politically accepted that such a system would bring about at least as much local human food security and, ultimately and more importantly, positive GHIs, as those that are currently produced by the herding-gathering system.

A significant obstacle to making such a case lies in Kasana's third reason. It might be argued that interests 6 and 7 are really important, but that their significance should nevertheless be outweighed by other interests. Even if we grant that crop agriculture injures and kills more animals than pastoralism, a moral theory that gives some weight to interests 1 and 2 might still favour crop agriculture due to its aversion towards ingesting animal products. Kasana might counter, however, that he does not share this aversion, or that it is insufficiently strong to question pastoralism. I think he may be right about the latter: by continuing with pastoralism, Kasana would choose the lesser evil compared to jeopardising local food security.

Another challenge rests in the argument that Kasana fails to safeguard interests 3 to 6 . It might be argued that the animals who are harmed by crop agriculture, for example through pest management, are less significant than the animals who are harmed by Kasana. For this argument to work, however, it would need to be argued either that the former are less closely related to us or that they possess less developed experiential capacities. The problem with this is that crop agriculture does harm large numbers of very significant animals, for example mice and rats (Fischer and Lamey, 2018).

Whereas Kasana may be right that the harm inflicted on other animals through crop agriculture in Kenya and Tanzania far outweighs the harm that Maasai pastoralism inflicts on nonhuman animals, it might be argued that he should be much less concerned about causing accidental harm (interest 6 ) - the main form of harm inflicted on nonhuman animals by crop agriculture - than about causing deliberate harm (interest 3), the main form of harm inflicted by pastoralism. Whilst adopting this view, I doubt whether it provides a sufficient ground to reject Kasana's case. The reason for this is that Kasana kills animals fairly infrequently, preferring to use 
their blood and milk instead, whereas crop agriculture routinely kills millions (Sabrosky, 1953).

Numbers matter: whilst in many situations killing accidentally, but foreseeably, may be less problematic than killing deliberately (where the latter is not done to benefit the animal), it does not imply that the foreseeable, but unintended killing of one million animals is better than deliberately killing one animal. Another point in his favour is that Kasana kills animals swiftly, causing minimal distress, whilst the animals who are killed through crop agriculture do not benefit from quick deaths. Whilst minimal tillage systems may reduce animal deaths significantly, some form of pest control can hardly be justifiably avoided in crop agriculture as its avoidance would compromise human food security quite significantly.

A final challenge to Kasana's case stems from a consideration of interest 7, our interest in the integrity of nature. As this concept should be understood in terms of an interest in allowing nonhuman nature to function autonomously, it might be argued that Kasana fails to pay sufficient attention to the fact that the domestication of animals involves a significant interference with the autonomous processes of nature. He might retort, however, that crop agriculture relies on the domestication of plants and involves an even greater infringement. Whilst it may not seek to control the lives of animals in the same way that pastoralism does, it nevertheless affects their lives, as well as the lives of other organisms, profoundly. Particularly where monocultures are used, crop agriculture alters landscapes significantly. The pastoral landscapes used by the Maasai, by contrast, resemble wild landscapes more closely. As much of the land in Kenya and Tanzania is relatively dry, compromising crop yields unless surface or ground water is applied - another significant sustainability issue (Marrin, 2019), I am not convinced that Maasai pastoralism presents a more significant concern in relation to interest 7 compared to crop agriculture in Kenya and Tanzania. To conclude this case: there is no moral case against Maasai pastoralism. Their continued reliance on blood, milk, and flesh from their herds must be embraced.

\section{Case 3: Gary the Scot}


Gary is a Scot who keeps cows, bulls, and sheep for their flesh. He feeds his animals from plants that grow on his farm, without relying on any arable crops. His animals survive the winter by feeding on grass, silage, and hay. Gary knows that he inflicts harm, but he believes that this is justified because of interest 8, for several reasons:

1/ It provides greater food security for agronomic reasons. The area in which he lives is not very suitable for crop agriculture (Morgan-Davies, Wilson, \& Waterhouse, 2015). Gary thinks that farming animals is preferable as there is too much rain, a significant risk of frost, and insufficient sunshine. Gary is aware that new genetic variants of traditional crops and greenhouse technologies might improve this situation, but he believes that no other form of agriculture could provide greater food security from his land. Whilst it is suitable to grow grass and a small variety of other plants that are eaten by nonhuman animals, he thinks that it could not grow much else. In addition, ploughing the land causes land degradation, including soil erosion, jeopardising the long-term capacity of the land to nourish people. Gary knows that his farm also produces negative GHIs, but he thinks that crop agriculture would produce more negative GHIs to obtain a comparable unit of food.

2/ It provides greater food security for personal and social reasons. Gary believes that some people might be able to convert his farm successfully to arable agriculture or some other enterprise, but he has greater faith in farming animals. He lacks knowledge about arable or other technologies. Animal farming, by contrast, is in his blood, as his family has been managing the same farm, using similar methods, for generations. Gary thinks that he would take a great personal risk, including a risk of bankruptcy, if he abandoned animal farming. To provide sufficient food security for his family, he thinks that the best option is to remain committed to the farming of animals. 
3/ Gary also considers the impacts upon nonhuman nature, recognising the importance of interests 3 to 7 . He claims that crop agriculture injures and kills more animals and that it undermines the integrity of nature, a concept that he associates primarily with maintaining the land's capacity to support good grass.

\section{Evaluation}

The justifications used by Gary are similar to Kasana's. The question must be asked, however, whether they work equally well in Gary's context.

With regard to the first reason, it must be recognised that many areas in Scotland are not very suitable for crop agriculture. If we imagine a worst case scenario where, even with the best expertise, it would not be possible for Gary to have a viable arable farm, it must be asked whether this mounts a good case for the farming of animals. It is important to consider that the short-term gains that may be derived from Gary's farm might compromise longer-term human food security. It may do so directly by Gary's animals' contribution to climate change. If Gary lives in an area that is unsuitable for arable farming, it may not be very suitable for animal farming either. If growing conditions are relatively unfavourable for all plants, Gary's animals will live a long time before being slaughtered, raising their relative greenhouse gas contributions compared to animals who fatten more quickly. The problem with this is that climate change disrupts agriculture, compromising human nutrition in the long term. Gary's farm may also compromise human food security indirectly, by the opportunity costs of using the land in this way. Whilst the land on which Gary keeps his animals may not be suitable for other types of agriculture, if part of it was reforested with fruit trees and part of it was left to its own devices (rewilding), the loss of Gary's animal farm may be outweighed by the benefits associated with such a conversion. This is so because positive GHIs have been associated with rewilding, and the fruit trees could provide some nutrition, fuel, and timber, as well as help to mitigate climate change (Monbiot, 2014; Fairlie, 2010; Lorimer, Sandom, Jepson et al. 2015). 
With regard to the second reason, there may be a lack of social support for the conversion of Gary's farm. If Gary was a tenant farmer for one of the 1000 largest land owners who own more than half of Scotland (Hains, Hustedde, and Ricketts, 2013), he would be likely to manage a large amount of land. When the land is controlled by so few people, the most economical way to manage it might be to keep grazing animals due to the relatively large labour costs of other options. In this social climate, Gary might compromise his family's needs by turning his back on animal farming. A potential bankruptcy might also cause wider social disruption, for example an increase in local dependency on other areas or a decrease in local labour opportunities.

Even if it might be possible to convert Gary's farm successfully in spite of these pressures, it does not imply that Gary possesses the expertise to do so. Whereas education might rectify this situation to some extent, it may not do so sufficiently to avoid bankruptcy. In spite of the potential long-term benefits associated with a conversion, Gary might therefore argue that he should prioritise his family's immediate needs. This is a valid concern, and it underlines that our economy should be aligned with interest 8 . The problem is that it is not, and that the farming of animals in the United Kingdom is subsidised heavily to produce significant harms for marginal benefits (MorganDavies, Wilson, \& Waterhouse, 2015). In Scotland, sheep are the dominant farm animals, occupying around 3 million hectares, an area that equals about half the size of all the UK arable land (DEFRA, 2017; DEFRA, 2018). The problem is that this area produces a quantity of food with a calorific value that totals less than $1 \%$ of annual UK consumption (Monbiot, 2017). Whereas the health benefits provided by Gary are mainly for those who use the flesh and the wool that are produced on his farm, most harms are spread out thinly over wider society, nature, and future generations.

In spite of Gary's understandable concerns, I believe that Gary might compromise his own and others' health more if he continued on the same path. Giving adequate recognition to interests 1 and 2 demands that we tend to our aversion towards consuming animals. Like Kasana, Gary might argue either that he does not have such an aversion or that the aversion is outweighed by the health implications associated with abandoning his enterprise. In relation to the former possibility, I would 
argue that Gary may have suppressed the aversion, rather than that it would not exist. In relation to the latter, I would argue that Gary's situation is likely to differ in a morally relevant way from Kasana's. Gary and his family are less likely to experience significant hardship by giving up the farming of animals for flesh. If his alternative business failed, all who depended on it could still draw upon Scotland's relatively strong social security system, which helps those with insufficient means to reach a basic standard of health care.

With regard to the third reason, my judgement differs from Gary's in the weight that he gives to interests 3 to 6 . Both Gary and Kasana are justified in holding the view that ploughing the land imposes negative effects on other animals, but this does not imply that it is as problematic in Scotland as it is for the Maasai in Kenya and Tanzania. Whereas it may make no sense for Gary to plough his land as it may hardly be suitable for arable cultivation, it is likely that Gary and those who depend on his farm could increase their dietary reliance on other land in Scotland, and that this would be preferable. As Scotland possesses some land that is quite suitable for arable cropping but that is not currently used for that purpose, one option is to cultivate some of this land. An alternative, and better option would be to divert some Scottish arable land that is currently used to feed farm animals, to feed people directly, where harm could be reduced through the adoption of minimal tillage agriculture.

Gary might counter that, if the latter is not an option, for example due to a lack of political will, adopting the former option would not be preferable due to the fact that it would increase the harm that arable farming inflicts on nonhuman animals. I believe, however, that this harm is less significant than the harm imposed by Gary's farm. Gary should give more weight to his concern about the intentional infliction of harm upon other animals, particularly as the animals whom he rears are relatively closely related to us and are likely to be capable of having rich experiences. The intentional infliction of harm upon animals is, in many situations, more problematic than the foreseeable, but accidental infliction of harm, where much harm in arable farming falls into the latter category. Whereas Kasana cannot avoid the intentional infliction of harm without facing 
severely negative consequences for himself and his family, the consequences would not be quite so severe for Gary.

In relation to interest 7, it must be recognised that, on this planet, few things exist that do not bear the mark of humanity. As people interfere with most natural processes on the planet, it is appropriate to speak of relative degrees of integrity, depending on the extent of human interference. In this light, it must be pointed out that people have altered the Scottish landscape profoundly, primarily through the introduction of sheep and the eradication of the wolf. Gary's farm perpetuates this trend as grazing competes with tree growth. Apart from the more narrowlyconceived functional reasons to support an increase in tree cover in Scotland, for example to mitigate climate change, to increase the production of fuel and timber, and to enhance biodiversity, I believe that we all stand to gain enormously from allowing much of the less productive land in Scotland to rewild. Human health is undermined significantly by the demise of places that bear relatively few marks of human culture. Whereas Maasai pastoralism also impacts upon the environment, the more constant grazing pressure that is exerted by many animals who are kept in enclosures alters the landscape more significantly than the sporadic grazing of the Maasai's roaming animals.

To conclude this case: If Gary stops farming animals for flesh, he may face bankruptcy, a greater reliance on others to provide food and other materials for his and his family's needs, a greater dependency on fossil fuels, a reduction in living standard, and ill health associated with the loss of his sense of self. The potential demise of his farm may also result in negative effects upon those who depended on his business. These negative GHIs may be outweighed by the positive GHIs of such a move, including: an improvement in moral health as animals are no longer used as objects for human consumption without good justification; a reduction in the deliberate infliction of harm upon animals, especially upon those who are closely related to us; and a reduction in actions that undermine nature's integrity. 
It is important to recognise that, if Gary decided to stop farming animals for flesh, his animals would continue to undermine nature's integrity for a considerably longer time, as Gary would need to keep his animals until they became very ill or died, and prevent them from reproducing. If Gary were to face significant hardship by doing so, for example through a lack of social support, it would be acceptable for Gary to use his animals for financial or nutritional benefits as he should prioritise his and his family's vital needs. However, if Gary or his family are unlikely to experience significant hardship by surrendering the farming of animals in order to provide human food, they ought to do so. If others can support Gary to do the wrong thing, which they currently do by paying for some of his negative GHls, they should also be expected to help him to do the right thing. The vegan project is the political project that strives for legal changes to impose vegan diets on many people and that would help people who are in Gary's position to make the transition towards a world wherein human diets protect our interest in holistic health (Deckers, 2016, p. 107130).

\section{Conclusion}

I described and discussed three cases related to the consumption of animal products, arguing that the answer to the question when such products should be included in human diets varies with one's ecological context. In other contexts, this question should also be addressed by carefully balancing all the specific interests that comprise our general holistic health interest, including our seven interests in avoiding the consumption of animal products. Case 1 highlights the relevance of interests 1 to 5 , and cases 2 and 3 that of interests 6 and 7. In all cases, it is argued that some specific interests ought to outweigh others as, in every decision, our holistic health interest (interest 8) should prevail. Many dietary decisions that people make today fail to safeguard this interest.

\section{References}


Aiking, H. (2019). Environmental Degradation - An Undesirable Output of the Food System. In: Sabaté, J. (ed.). Environmental Nutrition: Connecting Health and Nutrition with Environmentally Sustainable Diets. Place: Elsevier, p. 123-138.

Deckers, J. (2011). Negative 'GHIs', the Right to Health Protection, and Future Generations. Journal of Bioethical Inquiry. 8(2). p. 165-176.

Deckers, J. (2016). Animal (De)liberation: Should the Consumption of Animal Products Be Banned? London: Ubiquity Press.

Deckers, J. (2017). Why “Animal (De)liberation” Survives Early Criticism and Is Pivotal to Public Health. Journal of Evaluation in Clinical Practice. 23(5). p. 1105-1112.

Department for Environment, Food and Rural Affairs (DEFRA). (2017). Farming Statistics. Final crop areas, yields, livestock populations and agricultural workforce.

https://assets.publishing.service.gov.uk/government/uploads/system/uploads/attachment_data/file /670004/structure-jun2017final-uk-21dec17.pdf

Department for Environment, Food and Rural Affairs (DEFRA). (2018). Agriculture in the United Kingdom 2017.

Fairlie, S. (2010). Meat: A Benign Extravagance. East Meon: Permanent Publications.

Finke, J. (2003). Maasai - Religion and Beliefs. [Online] Available from:

http://www.bluegecko.org/kenya/tribes/maasai/beliefs.htm [Accessed: 31 May 2017]

Fischer, B. and Lamey, A. (2018). Field Deaths in Plant Agriculture. Journal of Agricultural and Environmental Ethics. 31(4). p. 409-428.

Francione, G. (2010). Animal Welfare and the Moral Value of Nonhuman Animals. Law, Culture and the Humanities. 6(1). p. 24-36.

Hains, B. J., Hustedde, R., and Ricketts, K.G. (2013). 21st Century Crofting: Strengths and Opportunities for Community Development. Journal of Agriculture, Food Systems, and Community Development. 3 (3), p. 47-60. 
Hughes, L. (2006). Moving the Maasai: A Colonial Misadventure (St Antony's Series). Basingstoke: Palgrave Macmillan.

Lorimer, J., Sandom, C., Jepson, P., Doughty, C., Barua, M. and Kirby, K.J. (2015). Rewilding: Science, Practice, and Politics. Annual Review of Environment and Resources. 40. p. 39-62.

Mahoney, B. (2017). Vegetarianism, Moral Sentiment, and the Aesthetics of Disgust: Reconfiguring the Trajectory in the Ethics of Eating. English Language Notes. 55 (1-2), p.41-51.

Marrin, D. (2019). Natural Resource Constraints on the Food System. In: Sabaté, J. (ed.).

Environmental Nutrition: Connecting Health and Nutrition with Environmentally Sustainable Diets.

Place: Elsevier, p. 55-74.

Monbiot, G. (2014). Feral. Rewilding the Land, Sea, and Human Life. London: Penguin Books.

Monbiot, G. (2017). https://www.monbiot.com/2017/01/11/explanation-of-the-figures-in-grimreaping/

Morgan-Davies, C., Wilson, R. and Waterhouse, A. (2015) Use or delight? History of Conflicting Hill Land Uses in Scotland - A Review. Scottish Geographical Journal. 131 (2). p. 98-122.

Nganga, P.M. (2013). Ethics, Values and Norms: Explaining Conflict Management in the Maasai Community, 2009-2012 (MA dissertation, Institute of Diplomacy and International Studies), Nairobi: University of Nairobi.

Paez, E. (2017). The Pitfalls of Qualified Moral Veganism. A Critique of Jan Deckers's Holistic Health Approach to Animal Ethics. Journal of Evaluation in Clinical Practice. 23(5). p. 1113-1117.

Sabaté, J., Harwatt, H., \& Soret, S. (2016). Environmental Nutrition: A New Frontier for Public Health. American Journal of Public Health. 106 (5). p. 815-821.

Sabrosky, C. (1953). How many insects are there? Systematic Zoology. 2(1). p. 31-36.

Springmann, M. (2019). Can Diets Be Both Healthy and Sustainable? Solving the Dilemma between Healthy Diets versus Sustainable Diets. In: Sabaté, J. (ed.). Environmental Nutrition: Connecting Health and Nutrition with Environmentally Sustainable Diets. Place: Elsevier, p. 197-228. 
Talbot, L.M. (1986). Demographic Factors in Resource Depletion and Environmental Degradation in East African Rangeland. Population and Development Review. 12 (3). p. 441-451.

Wagh, K., Bhatia, A., Alexe, G., Reddy, A., Ravikumar, V., Seiler, M., Boemo, M., Yao, M., Cronk, L., Naqvi, A. and Ganesan, S. (2012). Lactase Persistence and Lipid Pathway Selection in the Maasai. PloS one, 7 (9). p. e44751. 